\title{
Genomics, obesity and enhancement: moral issues regarding aesthetics and health
}

\author{
MAARTJE SCHERMER ${ }^{1}$
}

\begin{abstract}
Human enhancement is the term used for applications of biomedical knowledge that aim to improve human form or functioning beyond what is necessary to restore or sustain good health. Genomics is one of the research-areas that promises to offer such possibilities in the near future, and body weight - especially over-weight and obesity is one of the human characteristics at which these will be directed. This paper offers an overview of some of the moral issues that the subject of enhancement raises when related to obesity and genomics. After a brief discussion of the different perspectives on obesity and on the meaning of the term enhancement, a framework is presented in which the moral issues at stake are organised according to perspective on obesity (health or aesthetics) and moral outlook (distributive justice vs private morality). An inventory is made of the different ethical discussions that possible future genomicsbased options for the prevention or treatment of obesity and overweight may evoke. These include justice, obligations with regard to life-style, the limits of medical practice and the value of food and food-cultures. Finally, some speculations are made with regard to future possibilities for genetic modification and "self-evolution".
\end{abstract}

\section{Introduction}

Research in genomics, at least in the popular image, holds the promise of great things to come - not only cures for diseases but perhaps also possibilities to improve and refine ourselves. The debate in bioethics on such possibilities, that have come to be known as "enhancement", has been going on for almost a decade. Developments in genetic knowledge and techniques form an important impetus for this debate. In this contribution I intend to provide an overview of the widely diverging moral questions that the subject of enhancement can raise when related to obesity and genomics. After a brief discussion of the different perspectives on obesity and on the meaning of the term enhancement, I will present a framework to order the various moral issues at stake. I will make some assumptions about the kind of interventions that genomics research might provide us with in the future and then go on to make an inventory of the different ethical discussions that these future options for the prevention or treatment of obesity and obesity related health-problems may evoke. The intention is to offer a broad overlook of the field rather than an in-depth analysis of any one specific concern.

\section{Health and aesthetic perspectives on obesity}

Nowadays, obesity is seen mainly as a health problem, and especially a public health problem. Warnings about the obesity epidemic abound. There is some discussion as to whether obesity is a disease in itself, or whether it (merely) is an important risk-factor 
for other diseases, such as cardio-vascular diseases, diabetes or arthrosis. Some critical commentators, however, have claimed that the health-risks of being obese are grossly overstated or even non-existent.

Obesity and over-weight can be considered from another perspective as well, that of aesthetics or physical beauty. This aesthetic perspective on weight used to be stronger but recently appears to have been overtaken by the health-perspective, at least in public policy and perhaps also in the perception of many ordinary people. When obesity and overweight are considered from the aesthetic perspective, the remarkable different standards of physical beauty and bodily attractiveness of (especially the female) body stand out. Across cultures and over time, fatness has been appreciated quite differently. For example, in many less affluent societies - both past and present a sizable posture is associated with wealth and therefore considered attractive. Another example is that Marilyn Monroe, the sex symbol of the nineteen fifties, would be considered "fat" by present-day standards. What is considered to be beautiful does not always align with what is considered to be healthy. Although in some communities being fat is seen as a sign of health, it can and does lead to serious health problems. On the other hand, the present-day Western female beauty-ideal tends to be so skinny, that it can become quite unhealthy. For example, supermodel Kate Moss has a BMI of around 15 (18.5-24.9 being the normal range).

Obesity is often associated with a lack of self-discipline and the ideal nowadays appears to be "effortless thinness". This reminds one of the old sin of gluttony. Thinness therefore tends to be seen not (only) as healthier, but also as morally better than obesity. Lately, the interest in the healthcare costs of obesity - estimated to be $5.7 \%$ of the national health expenditure in the United States in $1998^{2}$ - intensifies this view of obesity as morally reprehensible. If fat people are to be blamed for their fatness, they are also responsible for the concomitant costs of their condition. In a collective healthcare system these costs are partly paid for by people who are not obese themselves. In other words, or so this line of argument goes, obese people wrongfully burden non-obese people with their self-incurred healthcare costs.

Finally, in the popular image, obese people are sometimes portrayed as sociable and enjoyable people, humorists who enjoy life and are "good company" (cf Roseanne Barr in her TV-show). However, as various sociological and psychological studies indicate, obese people are generally seen by the public as less attractive, and as having more negative personality traits than non-obese people. Prejudices abound and attitudes towards the obese are over all more negative than positive. Obese people are discriminated against in the areas of employment, education and healthcare. They have less chance to obtain jobs, are likely to earn less, and are considered to be lazy, indulgent, or even "repulsive" by a considerable percentage of nurses and medical students ${ }^{3}$.

\section{What is enhancement?}

Enhancement is a fairly recent concept in ethics, and is derived from the verb "to enhance" which means, according to Webster's dictionary: "to heighten, to increase, especially: to increase or improve in value, quality, desirability or attractiveness." 
Though this broadly describes what enhancement is about, it is difficult to come up with an exact definition of what enhancement is, let alone to determine exactly which technologies, procedures or medications fall in this category and which do not. Is losing weight a form of enhancement? It might be for someone who is overweight, but it is definitely not so for an anorexia patient. And if you are obese, does losing weight count as a form of enhancement, or is it simply a cure for a disease? Does it matter by what means the weight-loss is brought about? Should dieting and exercise be seen as "enhancement technologies"? Should appetite-diminishing drugs, genetherapy, or implanted brain-electrodes ${ }^{4}$ be considered as such?

Enhancement is often associated with making people "better than well" or going "beyond therapy" . Enhancement is thus more than making people "better" in the sense of curing them, or restoring them "back to normal". Enhancement is associated with reaching some state above or beyond the normal human condition, or with acquiring some capacities that are more-than-normal. But is the idea of being better than well applicable in the case of obesity, or more accurately, of weight? If not, using the term "enhancement" with regard to obesity appears inappropriate. Weight typically is a trait with an optimum, not a maximum quality. More (or less) weight is not always better; there is an optimal weight for everyone - enhancement in the sense of reaching an "even better" weight is simply impossible. Nevertheless, the term enhancement is also used for techniques and procedures that improve people in some way, even if this does not mean maximising a certain trait or capacity. Such improvements may either be improvements as compared to the average person, or as compared to the person's own natural state. Some changes that are personal enhancements are mere "normalisations" when compared to the average of the population.

The term enhancement is most often used with regard to physical traits of people, although mental capacities can also be the object of enhancement ${ }^{6}$. The means to enhancement - at least those means of enhancements that elicit ethical discussion are most often bio-technological, and work through physical interventions in the body. Interventions that change the environment, or that change people through behavioural or cognitive therapy, for example, are not usually included in discussions about enhancement. Rather, these are seen as the kind of "natural" interventions that the "unnatural" and potentially problematic bio-technological enhancements are contrasted with. Although I do not agree with this overly simplistic view, I will follow this usage here and focus on interventions that aim at changing the body, not on those interventions directed to the environment or to personal behaviour ${ }^{7}$.

According to Juengst, enhancement functions as a concept in two distinct discussions: first, the discussion on the proper limits of biomedicine (including discussions on the limits of medical practice, the proper role for doctors, and the funding of medical services), and second, the discussion on the ethics of self-improvement ${ }^{8}$. In the first context, enhancement serves as a boundary concept, marking off treatment from enhancement, or medical necessity from mere luxury. In the second context, the concept of enhancement functions more like a signpost, warning us for the various moral issues that are at stake in our quest for self-improvement. While the first discussion is clearly relevant for public policy - especially the distribution healthcare 
services - this is not directly clear for the second discussion, which focuses more on personal morality and questions about the good life. In liberal societies these have traditionally been confined to the private sphere. This does not mean, however, that people do not worry or deliberate about such moral issues, nor that a public discussion about them is impossible or absent.

\section{Framework}

If we combine the two important perspectives on obesity: the health perspective and the aesthetic perspective, with the two debates in which the concept of enhancement functions, we get a cross table of four distinct (though intertwined) moral debates. I will use this framework as a heuristic device to discuss the different moral questions that enhancement and obesity raise. Some of the moral questions clearly belong to one of the four boxes, while others show more overlap. In some cases, the box in which a certain question is placed depends on one's presuppositions and one's framing of the problem. As a rough division into four separate fields of debate, however, I believe the following scheme works well:

\begin{tabular}{|l|l|l|}
\hline & Health perspective & Aesthetic perspective \\
\hline $\begin{array}{l}\text { Discussion: Distributive } \\
\text { justice \& limits of health- } \\
\text { care }\end{array}$ & Who should pay? & Proper role of doctors? \\
\hline Discussion: Personal ethics & Obligation to be healthy? & $\begin{array}{l}\text { Proper means and proper } \\
\text { ends? }\end{array}$ \\
\hline
\end{tabular}

In the next part of this article, I will discuss these four issues. First, however, let us look briefly at the possibilities that genomics research creates to actually influence human weight and weight-related health. Can genomics "enhance" our weight? Clearly, as set out in the previous section, it depends in part on the definition of enhancement whether any measures to influence people's body weight or related health deserve the predicate "enhancement". Another issue is whether genomics will enable us to influence body weight in new and unprecedented ways, or whether it will significantly change existing ways, either qualitatively or quantitatively. Genomics research will probably provide us with more insight in the human metabolism and in the (patho)genesis of obesity. It will also probably influence the way in which we understand and classify obesity, although it cannot be predicted at forehand how this will turn out. One perspective on obesity that is influenced by genomics research is the idea that the stockpiling of bodyfat in situations of affluence is part of a "natural" reaction of the human body, because a buffer stock of energy is very useful in times of scarcity. From an evolutionary perspective, the ability to store energy is very useful in situations in which the availability of food is uncertain and varying - as it was when humans were still hunter-gatherers. This is called the thrifty gene hypothesis ${ }^{9}$. According to this hypothesis, the amassment of body fat is a potentially useful phenomenon, a way for nature to deal economically with energy. This view that obesity can be the result of a natural mechanism, which is useful and healthy under certain circumstances, is at odds with the view of obesity as a disease, at least when 
using a Boorsian concept of disease ${ }^{10}$. Boorsian concepts of disease rest on the idea of normal or natural bodily functions, which are disrupted in case of disease. Obesity might in this view constitute a risk factor for diseases but not a disease itself. The idea of an "obesogenic environment"11 also fits in this line of thought and opens up the possibility to see intervention directed to environmental factors that cause obesity as "medical" or "public health" interventions.

What exactly genomics research will render for the prevention or treatment of obesity is as yet far from clear. What is clear is that some people have a stronger disposition to become obese than others - not only because of their behaviour or social environment, but also because of genetic factors and the way their metabolism works. Perhaps it will one day be possible to alter this genetic predisposition through, for example, gene therapy, and thus to prevent obesity. It may also become easier to treat already existing obesity and overweight through new types of medication and pharmacogenomics. Another possibility is that the outcomes of genomics research would enable us to reduce the health-risks of being obese, for example by intervening in the process of arteriosclerosis, or by reducing diabetogenic effects of obesity. This would enable people to be fat but relatively healthy, taking away an important reason to reduce weight.

Because many ethical considerations with regard to obesity and genomics will depend on the details of the available prevention or treatment options, which are as yet unknown, I will here discuss some issues about the ethics of enhancement and obesity in a rather general sense. In doing so, I will sometimes anticipate or explore preventive or therapeutic interventions that are as yet non-existent.

\section{Four issues in enhancement and obesity}

\section{1) Obesity from a health perspective / distributive justice}

The two main and intertwined issues in this field of discussion are: do prevention and or reduction of obesity belong to the realm of medicine? And: who should pay for these interventions? It is often assumed that medical necessary treatments should be paid for using some collective or public health funds, whereas only the individuals who desire them should pay for enhancements. Consequently, the classification of an intervention as either therapy or enhancement becomes crucial in answering the question of who is going to pay for interventions. It thus becomes crucial to settle the question of whether prevention and reduction of obesity count as medical treatment or as enhancement.

At least some means of losing weight require medical intervention, such as gastric banding, or the use of fat-absorption blockers like Xenical. However, using medical means is not by itself enough reason to classify an intervention as properly belonging to the medical realm, or as eligible for public funding. Plastic surgery is a good example of this. In order to classify an intervention as treatment, the goals of the intervention count, too.

Interventions to reduce bodyweight often have a medical goal instead of, or as well as, the aesthetic goal. Either the goal is a "cure" for obesity, or it is risk-reduction - 
diminishing the health risks associated with obesity and severe overweight, like cardiac disease or diabetes. When obesity is understood as a disease, or as a serious risk-factor, losing weight must be understood as a form of medical treatment and not a matter of enhancement. In that case, it does belong to the medical realm and it should be paid from the general heathcare budget.

This approach is in line with a common account to distinguish between medical treatment and enhancement, the so-called disease based account. The disease based account entails that all conditions diagnosed as disease by medical criteria should be treated. However, in the absence of any pathological, medical problem, interventions are considered not as treatment but as enhancement. This is a simple and appealing model, but unfortunately, it quickly runs into problems.

First, the question of whether obesity is a disease or not, has not been answered definitively yet, and there is no consensus in the medical community. More fundamental, there are no uniform and uncontested criteria for what should be considered a "disease". Different concepts of disease all have their problems and it is, moreover, likely that genomics will influence and change our concept of disease.

Second, the disease-based account also has a problem with classifying prevention. Preventive medical interventions, like vaccinations, do not offer a cure for a diagnosed disease, and should therefore perhaps be considered enhancements. But that is not in line with current common practice.

This problem also becomes obvious when obesity is not seen as a disease in itself, but as a risk-factor for getting certain diseases. On such a view, losing weight becomes a form of prevention, just like vaccination. Or perhaps losing weight is more aptly compared to other forms of risk-reduction, like quitting to smoke, or taking more exercise. It is not obvious that these belong in the medical realm or should be paid for by public means because, on the view that is currently dominant, there is an important voluntary behavioural aspect to these health-risks, and this implies individual responsibility. Genomics might (or might not) change this view and lead to less emphasis on the behavioural aspect and on less personal responsibility for being obese. A similar shift in focus appears to take place lately with regard to smoking, which is seen more and more as an addiction, for which one can have a genetic disposition. Since smoking has a (partly) genetic cause as well as negative healtheffects, it should be treated medically, according to some ${ }^{12}$.

Another approach to the treatment-enhancement distinction in the context of healthcare funding is that of normal species functioning combined with a commitment to fair equality of opportunity ${ }^{13}$. Formal equality of opportunity means that all have equal rights, and effects of discrimination are corrected. Fair equality opportunity implies a "level playing field", requiring compensation for effects of the social lottery (Rawls), as well as (in Daniels' account) for some effects of the natural lottery.

This approach turns the previous discussion on its head. Instead of establishing what counts as disease and what consequently counts as treatment, in order to determine what properly belongs to healthcare and should therefore be publicly funded, this 
approach asks what kind of medical interventions we owe, as a matter of justice, to all members of society. It explains the moral importance of providing healthcare to all members of society and thus offers a rationale for the (public) provision of healthcare services. Health care should be distributed fairly, meaning that it should give citizens equal opportunities by restoring or improving their abilities to the range of functional capacities typical for members of their reference class. Healthcare is thus seen as one of society's means to preserve equality of opportunity for its citizens. Although the distinction between interventions that should be provided and those that are mere "luxury" does usually align with the treatment-enhancement distinction, this is not always the case, as we will see.

What does this imply for obesity? Does being obese impair the normal range of functioning? It can be argued that it often does. For example: it leads to a lower life expectancy, it leads to all kinds of diseases (like arthrosis) that in turn further limit normal functioning, and severely obese people cannot move around and do certain physical tasks as easily as slim people. Does obesity lead to unequal opportunities? Yes, it probably does. With a shorter life-expectancy, one does not have the same opportunities to lead a full human life; the physical impairments of being obese as well as the impairments of the associated diseases and social prejudices lead to less opportunity. On this account, obesity should be treated in order to restore the obese citizen back to a normal range of functioning and opportunity.

However, this account overlooks one important aspect of the problem: the question of how the citizen became obese in the first place. If everyone starts out with a normal body weight and a normal opportunity to acquire food and to exercise, but some eat too much, move too little and become fat, why would society have to make up for the consequences of these individual choices in life-style? When obesity is considered to be a "freely chosen" condition, it provides a clear case in which the treatmentenhancement distinction does not help to decide whether an intervention should be publicly funded. Although obesity may be a disease, and there may be a treatment for obesity, society is not obliged to provide it if the condition is self-inflicted.

The situation would change if genomics would show that some people have a very strong disposition to become obese (perhaps through a combination of slow metabolism, inborn character-traits like impulsiveness or weak self-control and a high set-point for bodyweight-regulation established through a faulty diet in early infancy) and this disposition would itself be considered a disability or a disease. It would limit one's opportunities to be so afflicted, because, for example, one would need to adopt a special eating and exercising-pattern. The relative importance or seriousness of such a limitation would of course be a matter of discussion, but it might support a claim to medical treatment of either the genetic disposition, or the resulting obesity.

Alternatively, such a predisposition could be considered "normal", but at the low end of the range of normal functioning. If it presented the same disadvantages as a "real" disease leading to obesity (for example a hormonal disbalance) it could be a matter of fair opportunity to "enhance" people with this genetic disposition ${ }^{14}$. This would be an example of a case where the treatment-enhancement distinction does not map onto the boundary between medical interventions that should be publicly funded and those that should not. 
As a third possibility, such a disposition to become obese could also be considered as a mere variation in normal functioning and in normal skills and talents, in which case it would not support a claim for publicly funded treatment. After all, according to the fair equality of opportunity account, individual traits lying within the normal range of human functioning do not need to be equalized. This account does not require a levelling of all individual differences or a redistribution of all skills and talents. From this perspective, a medical intervention to alter a disposition to become obese would be considered an enhancement and not a treatment. It would enable one to live more easily (less need for exercise and dieting) than others with the same genetic make up who were not enhanced, but it would not be considered a matter of justice to provide people with this enhancement.

\section{2) Obesity from an aesthetic perspective / distributive justice}

When we see obesity and overweight as aesthetic issues, rather than as healthproblems, the questions concerning the treatment-enhancement distinction change. The main question here is: does weight reduction for aesthetic reasons belong to the medical realm; is it a task for doctors? The question of whether or not weight reduction for aesthetic reasons should be publicly funded is a minor question here because - as is obvious from the previous section - it is disease or abnormal functioning that entitle one to publicly funded interventions, not aesthetic considerations ${ }^{15}$.

When no significant health issues are at stake, and weight loss is desired primarily for aesthetic reasons (think "overweight" rather than "obesity") what role should the doctor play? Does it belong to his profession to help people to look nicer? Or should he only treat diseases and cure illnesses and refrain from enhancing or improving people? Such questions are familiar from the debate about aesthetic surgery. An important difference is that weight loss can be acquired through various means, both medical and non-medical, whereas aesthetic surgery always requires substantial medical intervention. Several considerations are relevant here.

First, of course, the risks involved. Whereas there is little or no risk attached to lifestyle advice, such as dietary rules or exercise programs, pharmaceutical interventions will probably have side-effects and risks attached to them. Whereas a professional balancing of risks and benefits in case of health-threatening obesity may end up favourably, it may turn out unfavourable if only aesthetic appearance, and not health, are involved.

A related question is whether the balancing of risks and benefits is and should be a merely professional one. Should not the patient (or in this case perhaps better, the client) be allowed to make his or her own deliberations? In general, patients are allowed to refuse medical interventions if they do not agree with the doctor's assessment of risks and benefits, but they cannot demand interventions that the doctor considers unprofessional. Especially in the case of enhancements, this means that doctors do not have to do everything their patients desire; and that sometimes it would even be unprofessional to do so. 
A second important question is what the proper task or role of medicine is. Some say it is to treat diseases, others say it is to maintain or restore normal functioning; still others claim that it is to relieve suffering. On the first account, helping people lose weight for aesthetic reasons is not a task of doctors; on the last account it might be, if the person in question suffered a lot from her overweight. However, in that case, one would not be inclined to call the intervention a form of "enhancement"; rather it would be considered a form of treatment, just like correction of protruding ears is. In discussing the proper role of medicine and of doctors, the treatment-enhancement distinction is not proving very helpful. Rather, it appears to be a reformulation of the question.

Finally, even if we could settle the dispute over the proper tasks of medicine, would that imply that doctors are never allowed to use their knowledge and skills for reasons outside this medical domain? Liposuction for moderately oversized thighs would probably not fall within any definition of the "proper tasks of medicine" but does that mean that doctors may not offer it to people, as they now do in all kinds of beautycentres and private clinics? I believe that apart from safety considerations there is little reason to prohibit this. Perhaps, though, we should admit that such practices have little to do with traditional medicine and are better understood as "schmedicine" ". Whereas doctors might feel morally obliged to stick to their corebusiness, "schmocters" would have no such limitations; they would simply be entrepreneurs offering services based on biomedical knowledge and skills to consumers in a free market. Whatever the possibilities that genomics research is going to provide to keep one's body in shape, they will probably all be used by these schmocters and their beauty-seeking clients.

With the idea of schmocters as a new form of medical entrepreneurship, we have drifted a long way from the question of who should pay for the medical costs of weight loss for aesthetic reasons. In as far as reasons are purely cosmetic, collective funding seems out of the question. It would be labelled as an enhancement, in the sense of "mere luxury", as opposed to medically necessary treatment. One way to avoid this conclusion would run via an appeal to psychological distress and suffering caused by the overweight. Just like some other cosmetic interventions are paid if they will alleviate suffering (the protruding ears), so an overweight person may claim a right to liposuction, an anti-fat pill, or a new genomics-based intervention, because he is suffering from his looks and experiences psychological distress because of them. Another way would be to appeal to the social disadvantages and unequal opportunities that being (severely) overweight brings with it, like decreased chances on the jobmarket. These appeals would not stand much chance if the prevailing opinion would still be that overweight is one's own fault and can best be remedied through diet and exercise. However, if overweight would come to be seen more as a matter of bad luck, for example by the discovery of a genetic dysfunction causing overweight, this would make a claim on some form of collectively-funded treatment, even for cosmetic, psychological and social reasons, a lot stronger.

\section{3) Obesity from an aesthetic perspective / personal ethics}

Since in our society being fat is often equated with being ugly, one way to enhance physical appearance is to lose weight. The billion-dollar industry surrounding body- 
shape techniques and weight-loss products shows how many people (especially women) are fighting with their own bodies to enhance their looks and improve their health. Any "easy fix" that genomics research might render for overweight would probably be welcomed. The moral discussions this provokes mainly concern "personal ethics": questions about the good life, about virtues and about authenticity and freedom of choice. New genomics-based possibilities for preventing or treating overweight and obesity, and shifts in the way these conditions are perceived will also have repercussions for these moral discussions.

A first concern in this field of discussion is that enhancing oneself through medication or technology is, indeed, an "easy fix", and not as good or as worthy of respect as enhancement brought about by one's own efforts ${ }^{17}$. With regard to bodyweight, our attitudes on this point seem to be very ambivalent. On the one hand, obesity is associated with gluttony, sloth, and lack of will power. As I will discuss more extensively below, this view is problematic from a moral perspective, because it stigmatises people based on prejudices and stereotypes ${ }^{18}$. Nevertheless it is a common view, and losing weight is therefore often not only perceived as a practical matter, but also a moral one. It is seen as a way to practise and show off the virtues of selfdiscipline, moderation, determination and diligence. Losing weight should be done through effort and hard work: physical exercise and fierce self-restraint with regard to food. From this perspective, losing weight is a form of self-improvement through effort and virtue, and bypassing this route with the help of a pill or technology is felt to be morally inferior.

On the other hand, however, the success of feeding substitutes, herbal extracts and other devices that promise instant thinness shows that we do not really feel this moral pull so strongly. We do not massively blame people for using these "easy fixes". Perhaps, however, this is partly due to the fact that present pills and feeding substitutes merely promise but not really provide an easy fix. It does take effort, selfrestraint and will-power to continue most of the diets, food-substitute programmes and other slimming technologies. But how would our moral appraisal change if a really effective easy fix were to become available; if one could eat too much, too fatty food, and not exercise at all, and still remain thin through a pill?

Another issue that is often raised concerning enhancement of physical appearance is that of voluntariness versus social pressure. It has often been remarked that beauty ideals can be oppressive and can lead to social exclusion of those who do not live up to them. Social pressure to use available techniques to enhance oneself and adapt one's appearance to socially accepted norms might undermine the free choice of the person in question. This issue has been discussed extensively with regard to cosmetic operations and breast augmentations for women. A convincing argument has been made that although women are influenced by beauty-ideals this does not necessarily diminish their free or autonomous choice to use cosmetic surgery ${ }^{19}$.

At present, social pressure to lose weight is usually not considered to be so serious as to compromise the free choice of people who decide to lose weight, though some supporters of the obesity movement argue that it does and that their choice to be fat and beautiful is not respected by society. Indeed, were more options to become 
available to stay thin or lose weight easily, the more "abnormal" a fat figure would become. Social pressure to use all available means would then probably increase.

A special feature of overweight that makes the issue of voluntariness somewhat less problematic than in the case of cosmetic surgery, is that (severe) overweight has negative health effects in addition to cosmetic disadvantages. Wanting to lose weight is not merely a matter of beauty and ever-changing fashion, but also a more objective matter of health. This means that fat people have some reason to want to lose weight, apart from any fashion norms or related social pressure. Imagine, however, that the outcomes of genomics research would somehow make it possible to reduce the detrimental health effects of obesity so that one could be both fat and healthy. In that case, the health argument for losing weight would disappear, and the aesthetic argument would be the only one left. This would most likely shift the discussion on free choice and social pressure. Either being fat would not be considered to be so bad anymore, since it would no longer cause serious health-risks, or it would still be considered as deviant and un-aesthetic, despite it not being a health risk anymore. In the first event, social pressure to lose weight would diminish; in the second case, social pressure would remain high but would be more problematic than before, since it would rest only on social and aesthetic norms.

At the other end of the weight-spectrum, social pressure is also often claimed to be a problem. It is claimed that beauty norms and social pressure influence young girls' eating and dieting behaviour unfavourably, and affect the prevalence of anorexia nervosa. Apart from the question of whether this claim is justified, it is not clear that it is the social pressure itself that is most problematic here. Young girls' decisions to have tattoos or to "pierce" various body-parts are probably made under the same kind of social pressure, but this is not seen as very morally problematic. Rather, the question is whether the norm of thinness is not a "suspect norm", based on discrimination or prejudices and with detrimental effects.

Norms of appearance are morally suspect, according to Margaret Little, "when their content reflects, flows from, and reinforces a system of beliefs, attitudes, and practices that together involve deep injustice" ${ }^{20}$. She gives the examples of racial prejudice (the norm that a whiter skin is better than a darker one) and gender stereotypes (a good woman is a good-looking woman). Is thinness, in this sense, a suspect norm? Does the norm of slenderness reflects or flows from a system of injustice towards fat people? Does it reinforce such an unjust system? I believe that this depends partly on the degree to which health, aesthetics, and prejudices are involved here and partly on the degree to which fat people can be held responsible for being fat.

In as far as obesity poses serious health risks and people generally want to be healthy, there is nothing inherently unjust in having a social norm that favours thinness. In as far as the norm of thinness is based on aesthetic reasons, it also need not be unjust; norms of physical beauty and attractiveness always favour some people over others, but as Little remarks ${ }^{21}$, this is not unjust but merely unfortunate for the less endowed. Aesthetic or beauty norms, however, tend to be different and often stricter for women than for men and in that sense can be unjust. Women are judged more on their looks than men are, and the norm of thinness reflects this. 
Perhaps the most "suspect" aspect of the norm of thinness is that it incorporates ideas about behaviour and character of obese or overweight people as well as negative attitudes towards them. As mentioned before, obesity is associated with notions of guilt, sin, and weakness of will. Judgements of appearance thus tend to become judgements of behaviour and character at the same time. People are often considered responsible for their obesity or overweight, while in fact they often have less control over their own weight than others think. There are genetic, but also social, psychological and socio-economic factors that play significant roles. Individual behaviour is important, but it is not easy to change one's lifestyle. Losing weight can be a real struggle that takes effort and will-power even if it is in the end unsuccessful. Also, some people may indeed choose to stay fat because they like eating and dislike exercise; this may be a lifestyle choice that has nothing to do with "weakness" or bad character $^{22}$. On any account, it is unfair to stigmatise people and draw conclusions regarding their character based on their appearance. I believe this aspect of the norm of thinness is indeed suspect, but it is very difficult to disentangle it from the aspects of health and aesthetics.

Finally, it must be recognized that the norm of thinness tends to function in practice in a "suspect" fashion. It is clearly unjust to discriminate against fat people in the workplace, at school or in other social institutions where a person's weight and appearance are irrelevant for his performance or functioning, but it clearly happens ${ }^{23}$. The health and beauty-based norm of a slender appearance then oversteps its proper limits and becomes a discriminating norm.

When a norm is "suspect", techniques and measures to help people to conform to this norm can be accused of being complicit with the unjust system, and of exacerbating prejudice and discrimination. By bleaching one's dark skin in order to look whither, for example, one acts as an accomplice to a system that discriminates dark-skinned people. Once again, as long as health is clearly involved, measures against severe obesity cannot easily be accused of being complicit with an unjust and discriminatory system $^{24}$. We should be careful, however, that the justification of the norm of thinness in terms of health does not overstep its limits. By treating even slight overweight the same as obesity, despite the fact that overweight poses no or only limited health risks, the mainly cosmetic problem of overweight is turned into a medical problem. Moreover, new (genomics-based) options to reduce weight could be accused of complicity if they were marketed as means to improve appearance in people - most likely women - with normal weight or slight overweight, with an appeal to genderbiased beauty norms, or if they contributed to stigmatisation by stressing individual behaviour and character.

\section{4) Obesity from a health perspective / personal ethics}

When obesity is considered from the perspective of personal ethics and health, the question of enhancement can be rephrased as follows: is there a moral obligation to enhance our own health; and if so, how much effort is required and which means are appropriate? Here, issues of responsibility for health and the value of health relative to other values are important. 
In liberal societies, people are entitled to live according to their own views of the good life, and this implies that people can live according to diverging value patterns. Health is often seen as a basic value, because it is a precondition to realize most other values or aims in life. Bad health usually decreases one's life expectancy and also one's quality of life and whatever one's view of the good life, these are prima facie bad things. It can therefore be expected that people, as a mater of prudence, look after their health. However, this does not imply that health is always more important than other things, or that one should always do everything in one's power to stay healthy. Rather, one will always have to balance the value of health, and the effort it costs to maintain or regain health, against other values and aims in life. For example, a nurse tending on influenza-patients puts her own health at risk, but does so because it is her task and her responsibility. The aim of looking after the sick and doing a good job is more important than preventing every possible risk to her own health. A gourmand may well find the pleasures of eating more important than the health risks of being over-weight. And anybody with a sedentary job and a busy working-schedule might find his career, his family or his rare spare time more important than spending hours in the gym to do healthy exercises.

Taking care of one's health is more a matter of prudence and lifestyle than of morality; a matter of personal choice, rather than a public duty. It can be reframed as a matter of public morality, however, when other people are made to pay for one's carelessness regarding one's health, as can be the case in collectively funded healthcare systems. This brings us back to the issues of distributive justice discussed earlier. Moreover, a condition like obesity can become a public problem if it exists on such a massive scale that social interactions and relationships are disrupted. In the United States, almost $30 \%$ of obese people hardly leave their homes anymore because of their obesity ${ }^{25}$.

A very important question is how much we are willing to do to enhance our health: how much value do we attach to it as compared to other things, and how much effort do we want to invest in it? With regard to obesity and overweight, it has been remarked that the "war on obesity" and the extreme emphasis on the health-aspects of food and drink repress attention for other aspects of eating ${ }^{26}$. For example, the social dimension of eating and drinking may become neglected when food is merely seen as potentially fattening - it is not much fun going out to dinner with someone who is on a bread-and-lettuce diet. Another example is that specific eating cultures of various countries or ethnic groups may be suppressed for reasons of health: the Mediterranean kitchen is said to be healthy, but traditional Dutch cuisine should be banned from our tables because it contains too much fat meat and gravy. Moreover, production norms intended to reduce health risks can lead to prohibition of certain products, such as certain farm-made cheeses. Health risks are then deemed more important than the pleasure of eating well. For some gourmands "enhancing" health by deleting all kinds of exquisite food and drink from the menu would result in a diminished rather than enhanced quality of life.

For most seriously obese people, however, their weight has probably little to do with conscious choices, based on a balancing of values. They do not risk their health because they find eating so much more important than health, or because they 
consciously choose a life plan requiring little exercise, but because they cannot resist the temptation, because the lack knowledge about healthy food, because they have a slow metabolism, because they live in a obesogenic environment, or because of a number of other possible reasons. So, while the social and cultural risks of overemphasising the health risks of overweight or of certain food-patterns, and of medicalizing eating and drinking behaviour, should certainly be addressed, they should be evaluated in relation to the serious problems that obesity brings about.

Finally, I want to point out one more issue related to personal views on the good life, responsibility and health: the concern for children. Making health- and lifestylerelated decisions for our selves is one thing, but what about our children? Making lifestyle decisions that affect their health is quite something else. Parents are responsible (a typical form of role-responsibility) for their children, a responsibility that obviously includes the children's health and weight. Of course, other parties such as the government, schools, healthcare institutions or food-manufacturers have a responsibility here as well, but the primary moral responsibility for children rests with the parents. A healthy diet and healthy exercise habits are learned in childhood and obesity acquired at a young age has serious health consequences later in life. While passing on one's value patterns to one's children is an important part of the upbringing, and parents are to a large extent free to raise their children according to the value patterns that they prefer, parents are not free to make choices for their children that seriously harm them or significantly impair their options in life. This goes for choices that lead to obesity in children, but also for possible enhancements in children or future children (think of genetic modification or genetic selection) ${ }^{27}$. If medication became available to prevent or easily cure obesity, this might present parents with difficult dilemmas. Why deny your child snacks and sweets if there is medication to help him keep a proper weight? But on the other hand, why expose your child to possible side effects if you could also teach him a healthy lifestyle? Even harder questions are raised by possibilities for prenatal genetic testing or preimplantation genetic screening. If these techniques could identify embryos or foetuses with a high risk of becoming obese, how should parents, physicians and policymakers deal with that? Is preventing obesity in this way an acceptable way to enhance (the health of) our offspring?

\section{One step further: eugenics?}

Before I come to my conclusions, I would like to make some speculations and raise some questions regarding enhancement, genomics and obesity that are more futuristic than the previous reflections. Up until this point, I have tacitly assumed that whatever intervention would become available to prevent or cure obesity it would be used on an individual basis. However, some already speculate about more profound changes we might one day be able to make in our genome and thus in large groups of people, perhaps even our whole species. Suppose we could change our genome in such a way that we would be less prone to obesity, would this count as an enhancement? Would it be morally acceptable - or perhaps even morally required - to enhance our offspring by genetically engineering immunity to the obesogenic environment they will come to live in? 
If we accept the "thrifty genotype hypothesis", which states that through evolution we have developed survival mechanisms against periods of food scarcity, it could be argued that a natural trait that is useful under some circumstances has now "turned against us" and is causing obesity. Our genes have stayed the same, but our environment has changed from one of scarcity to affluence ${ }^{28}$. Ravussin claims that obesity has in our present environment become an "essential condition", and states that "what was an asset in early mankind history has now rapidly become a liability" 29 .

From this perspective, it would be an enhancement if we were to change our natural predisposition for economic energy-use to a more lavish use of energy. We would be able to eat as much (or more) than we do now, and move just as little, without becoming fat. We would not have to change our lifestyle to maintain a healthy body, but we would change our bodies to fit our lifestyle. Since this could be viewed as a way to adapt ourselves better to our present needs and environment it could be understood as a form of self-evolution ${ }^{30}$.

Apart from safety concerns - which would probably be massive - would this be a morally problematic form of enhancement? Would this somehow make us less human, or post-human; and if so, would that be a bad thing? Would such enhancements be purchased on an individual basis and would they perhaps only be affordable for the wealthy upper class? Or would they be provided and promoted as a public health measure to be used by all?

On a more fundamental level: is it wrong to "play God" like this, or to aim to change what nature has made us? There will certainly be people who will claim that it is. But why would we not adapt ourselves to new circumstances and aid our own evolution a bit? Is it morally better to control and alter our circumstances, rather than adapt our bodies?

And from a quite different perspective: would changing our genome to make us fatresistant be a fair thing to do in global perspective - would it be just towards all those people who have too little to eat, instead of too much?

These will be left open questions here, intended to show that there is much ethical discussion about enhancement beyond the questions I already raised. It is, however, not likely that we will have the option of designing and altering our genome at will available to us in the near future. Minor interventions, such as new medications, or genetic profiling and life-style advices, are much more likely to be developed.

\section{Summary and conclusions}

I have discussed some of the ethical issues related to obesity and human enhancement using a rough division into four problem-fields. It is clear, however, that this subdivision is not absolute and that there are connections and correspondences between the various discussions. 
Many of the questions discussed above are situated on the intersection of public and private morality. While people should be allowed to make their own choices and live (and eat) according to their own value patterns, it is clear that both eating behaviour and body weight are not strictly private matters, but issues of public concern as well. They are so most obviously because of public health concerns and the issue of fair distribution of healthcare costs, but also because of the cultural and social effects of an obesity-epidemic. These other-regarding effects of individual lifestyles place weight, eating and exercising issues on the borderline between private and public morality.

For many ethical issues, the demarcation between the health and the aesthetic perspective is important, but it is also clear that this is a contested and not always clear division. Health and aesthetic considerations do sometimes overlap or coincide, but can also diverge. Moreover, the developments in genomics may change the health and aesthetic perspectives, as well as their mutual relationship. The powers that genomics research will give us to intervene in the human body, as well as the changes it will bring about in (public) perception and attitude towards obesity and overweight, are not easily predicted and might go in many directions. Nevertheless, the ethical discussions that efforts to enhance people's weight and weight-related health will evoke will probably fall somewhere in the framework that I have sketched. Which of these ethical issues will prove most pertinent and what exactly the outcomes of the discussion will be, will depend on the further developments in both genomics and society.

\footnotetext{
${ }^{1}$ Erasmus Medical Center, Rotterdam, The Netherlands m.schermer@erasmusmc.nl

${ }^{2}$ A Wolf and G. Colditz. Current estimates of the economic costs of obesity in the United States. Obesity Research 1998; 6: 97-106.

${ }^{3}$ R. Puhl and K.D. Brownell. Bias, discrimination, and obesity. Obesity Research 2001; 9: 788-805.

${ }^{4}$ Experimentation is going on with Deep Brain Stimulation for obesity treatment. This was predicted already in: Health Council of the Netherlands. 2002. De toekomst van onszelf/The future of our selves. Den Haag, Gezondheidsraad.

${ }^{5}$ C. Elliott. 2003. Better than well. American medicine meets the American dream. New York, WW Norton \& Company and President's Council on Bioethics. 2003. Beyond therapy. Biotechnology and the pursuit of happiness. New York, Dana Press.

${ }^{6}$ President's Council on Bioethics, op. cit., note 5; M. Farah, J. Illes, R. Cook-Degan, et al., Neurocognitive enhancement: what can we do and what should we do? Nature Reviews Neuroscience 2004;5:421-425.

${ }^{7}$ Although one of the more exciting consequences of genomics research may be the possibility to influence human behavior through the body, or more precisely, the genes. Developments in both behavioral genetics and neuroscience are blurring the distinction between behavior and body. (For example: C.P. Kyriaciou. 2005. Behavioral genetics: sex in fruitflies is fruitless. Nature 2005; 436: 334-335; and numerous articles in the journal Genes, Brain and Behavior)

${ }^{8}$ E.T. Juengst. 1998. What does enhancement mean? In Enhancing human traits. Ethical and social implications, E. Parens, ed. Washington DC, Georgetown University Press: 29-47.

${ }^{9}$ J.V. Neel. Diabetes mellitus: a 'thrifty genotype' rendered detrimental by progress? American Journal of Human Genetics 1962;14:353-363.

${ }^{10}$ Christopher Boorse introduced one of the most influential conceptual models of health and disease: the biostatistical model. See: C. Boorse, Health as a theoretical concept. Philosophy of Science 1977; 44:542-73.
} 
${ }^{11}$ E. Ravussin and C. Bouchard. Human genomics and obesity: finding appropriate drug targets. European Journal of Pharmacology 2000; 410: 131-145.

${ }^{12} \mathrm{~J}$. Lucieer. Een andere kijk op verslaving: verslaving is een genetisch bepaalde chronische ziekte. [A different view on addiction: addiction is a genetically determined chronic disease] Medisch Contact 2005; 60: 852-854.

${ }^{13}$ A. Buchanan, D.W. Brock, N. Daniels and D. Wikler. 2000. From chance to choice. Genetics and justice. Cambridge, Cambridge University Press. And: N. Daniels, Normal functioning and the treatment enhancement-distinction. Cambridge Quarterly of Healthcare Ethics 2000; 9:309-322.

${ }^{14}$ D.W. Brock. 1998. Enhancement of human function: some distinctions for policymakers. In Enhancing human traits. Ethical and social implications, E. Parens, ed. Washington DC, Georgetown University Press: 48-69.

${ }^{15}$ In practice these reasons - health related and aesthetic - will of course not always be separated. Losing weight often has both aesthetic as well as health-related advantages and will often be pursued for both ends. Moreover, even if the patient only worries about looks, the doctor may still feel treatment is desirable because of the patient's health. However, the discussion about the health hazard of overweight and even obesity is not yet completely settled.

${ }^{16}$ E. Parens. 1998. Is better always good? The enhancement project. In Enhancing human traits. Ethical and social implications, E. Parens, ed. Washington DC, Georgetown University Press: 1-28.

${ }^{17}$ For a discussion and critique of this argument see M. Schermer, Enhancements, easy shortcuts, and the richness of human activities. Bioethics 2008; 22(7): 355-363.

${ }^{18}$ I. de Beaufort and S. Vandamme. 'No willpower required'. The slimming industry and the right to sell dreams. Medicine and Law 2008; 27:215-228.

${ }^{19} \mathrm{H}$. Wijsbek. The pursuit of beauty: forced aesthetics or a freely adopted lifestyle? Journal of Medical Ethics 2000; 26: 454-458.

${ }^{20}$ M.O. Little. 1998. Cosmetic surgery, suspect norms, and the ethics of complicity. In Enhancing human traits. Ethical and social implications, E. Parens, ed. Washington DC, Georgetown University Press: $162-176$ (p.167).

${ }^{21}$ Ibid

${ }^{22}$ It is not clear why "gluttony" or "weakness of will" should be thought of as moral failures at all, at least not from a liberal perspective. I thank an anonymous referee for bringing this point to my attention.

${ }^{23}$ Op. cit., note 3 .

${ }^{24}$ However, some measures might exacerbate discrimination and prejudice against obese people. For example, information campaigns that only stress individual behavior as the cause of obesity could strengthen the idea that obese people are "weak" or "bad". This is something we should beware of. ${ }^{25}$ G. Critser. 2003. Fat Land. Boston, Houghton Mifflin Company.

${ }^{26}$ For example M. Korthals. 2004. Before Dinner. Berlin, Springer; S. Vandamme and S. van de Vathorst. Neemt (gezond) en eet (met mate). [Take (healthily) and eat (moderately)]. Ethiek en Maatschappij 2007; 2:95-107.

${ }^{27}$ N. Agar. 2004. Liberal eugenics. In defence of human enhancement. Malden/Oxford, Blackwell Publishing.

28 "Us" refers here to people living in affluent societies or circumstances. It is an acrid fact that while one part of the world population is dying of too much food, the rest is still dying of too little.

${ }^{29}$ Op. cit., note 11, p. 135

${ }^{30}$ F. Fuchs-Simonstein. 2004. Self-evolution: the ethics of redesigning Eden. Tel-Aviv, ProBook. 